\section{artelogie}

\section{Artelogie}

Recherche sur les arts, le patrimoine et la littérature de l'Amérique latine

$15 \mid 2020$

Latin American networks: Synchronicities, Contacts and Divergences.

\title{
De Europa a América: la obra critica de Marta Traba y sus evoluciones
}

\section{Elsa Crousier}

\section{(2) OpenEdition \\ Journals}

Édition électronique

URL : http://journals.openedition.org/artelogie/4962

ISSN : 2115-6395

\section{Éditeur}

Association ESCAL

\section{Référence électronique}

Elsa Crousier, «De Europa a América: la obra critica de Marta Traba y sus evoluciones », Artelogie [En ligne], 15 | 2020, mis en ligne le 20 avril 2020, consulté le 05 août 2020. URL : http:// journals.openedition.org/artelogie/4962

Ce document a été généré automatiquement le 5 août 2020.

Association ESCAL 


\title{
De Europa a América: la obra critica de Marta Traba y sus evoluciones
}

\author{
Elsa Crousier
}

\section{Introduction}

1 Marta Traba, crítica de arte argentino-colombiana (1923-1983), es un personaje central de la teoría y la historia del arte latinoamericano. Podemos destacar en su obra dos períodos críticos: entre 1945 y los años 1960, adopta un punto de vista eurocéntrico, que toma como referencia el arte moderno europeo o "internacional"; pero a partir de los años 1960-65, dándose cuenta del peligro que representa la internacionalización de las artes latinoamericanas, empieza a reivindicar un arte moderno latinoamericano, que refleje o respete las identidades culturales regionales ${ }^{1}$.

2 El objetivo de este artículo es analizar la evolución de la crítica de arte de Marta Traba, porque las diferentes teorías que defendió entre los años 1945 y 1980 son representativas de los puntos de contacto y divergencia entre las escenas del arte moderno latino-americano de aquella época. Veremos entonces en qué medida se puede vincular esta evolución teórica particular con la definición del arte moderno en América latina a lo largo del siglo XX.

\section{Primer período crítico de Marta Traba: entre 1945 y los años 1960}

3 La primera etapa del pensamiento crítico de Marta Traba se caracteriza por una defensa activa - en América latina y más específicamente en Colombia -, de un arte moderno que siga las tendencias y los movimientos artísticos internacionales y sobre todo europeos ${ }^{2}$. Esta postura es debida a su trayectoria: estudiante de Letras en Buenos Aires, su formación en Historia del Arte es esencialmente autodidacta ${ }^{3}$, y Europa (Francia e Italia) la fascina. Sus primeros artículos publicados entre 1945 y 1946 revelan su interés por lo que ella considera como un "modelo": en su texto "El salón de la Asociación Estímulo", de 1946, evoca un "retraso" de las artes latinoamericanas, y 
considera que el arte europeo es la referencia, el modelo a seguir ${ }^{5}$. A partir de 1947, participa, como secretaria de Jorge Romero Brest, en las publicaciones de la revista Ver y Estimar ${ }^{6}$. Las orientaciones del famoso crítico de arte argentino, claramente eurocéntricas, confirman las de Marta Traba ${ }^{7}$.

Para continuar su formación, se traslada a Europa en 1948, primero a Italia (tres meses), y luego a París (un poco más de un año, durante el cual asiste a clases en l'École des Hautes Études de la Sorbona y en l'École du Louvre). Marta Traba regresa a Buenos Aires en 1950 con Alberto Zalamea, periodista colombiano, para dar a luz a su primer hijo, y vuelven a Italia juntos en 1953, durante un año (en el cual asiste a clases de Venturi y Argan).

5 Cuando Marta Traba llega a Francia, como muchos intelectuales latinoamericanos, en los años 1940-1950, ha idealizado la ciudad de París, por diferentes razones, como su modernidad intelectual, la libertad de las mujeres (llega en 1949, año de la publicación de El segundo sexo de Simone de Beauvoir), pero sobre todo por su producción artística, en particular de arte contemporáneo.

6 Debe esta fascinación a su formación universitaria en Buenos Aires, como explica la crítica de arte Victoria Verlichak: "[...] ir a París era una suerte de rito de pasaje, de graduación, existía tal cosa como un antes y un después de París en la vida profesional y creativa de artistas, escritores, músicos" (Verlichak, 2001: p. 96). Tal admiración por Europa en la creación artística latinoamericana tiene consecuencias directas en la visión que tienen los artistas de América latina. La experiencia del filósofo Enrique Dussel es relevante: explica que, en las formaciones que recibían los latinoamericanos en los años 1950, Europa era la norma y deformaba por consiguiente la percepción que tenían de sí mismos: «Para nosotros no había en Argentina de esa época ninguna duda de que éramos parte de la "cultura occidental" $»^{8}$. También explica que al alejarse de América latina "descubrió" que era latinoamericano. Es esta imposición de una cultura europea de la modernidad la que dio origen al tópico de un "retraso" latinoamericano.

7 Es finalmente con este aprendizaje y esta cultura que viene a instalarse en Colombia en septiembre de 1954 con la familia de su marido. A partir de su llegada, se integra en la vida intelectual bogotana y allí difunde su concepción del arte moderno, en una época en que el arte moderno "internacional" era desconocido y a veces rechazado en Colombia. Como ejemplo, podemos mencionar el debate que opone en 1969 a Marta Traba y el educador Agustín Nieto Caballero: él, figura destacada de la cultura colombiana, afirmaba que Picasso era "un estafador y que cualquier niño podía pintar sus cuadros" (Serrato Ramírez, 2013). Esa actitud explica las intervenciones a veces polémicas de Marta Traba en varios debates de la época ${ }^{9}$, cuya consecuencia fue, como dice Sol Astrid Giraldo E., que "Marta no se inventó el arte moderno colombiano pero le dio un lugar" (Giraldo E., 1998). Ella difunde entonces en Colombia la obra de los artistas europeos y norteamericanos más reconocidos, y da visibilidad a los artistas modernos colombianos.

En cuanto a sus teorías, Marta Traba explica que la recepción del arte moderno internacional por los artistas colombianos no debe consistir en una mera imitación de las obras, de los códigos estéticos o del estilo de otros $\operatorname{artistas}^{10}$, sino más bien en inspirarse en sus modelos teóricos y en los ideales que vieron nacer sus obras. Así, el arte moderno latinoamericano debe, según ella, construirse como un arte de alcance “internacional", en el cual predominen la independencia del artista y la autonomía del lenguaje plástico con respecto a su lugar de creación y su contexto socio-político. Marta 
Traba quiere, de este modo, que emerja una conciencia de la modernidad en Colombia que no es, en aquella época, una modernidad latinoamericanista -, y afirma: « No creo que haya un "arte colombiano", sino un arte que se realiza en Colombia » (Traba, Díaz, 1963: p. 1).

Al darles visibilidad, Marta Traba contribuye al reconocimiento por parte del público de artistas que consideramos hoy como los mayores representantes de la modernidad colombiana: Alejandro Obregón, Fernando Botero, Eduardo Ramírez Villamizar, Edgar Negret, y muchos más.

Si es reconocida como la crítica de arte que le da un lugar al arte moderno en Colombia, es gracias a una presencia mediática global: presenta programas de historia del arte a partir de $1954^{11}$, publica artículos en revistas y periódicos a partir de $1955^{12}$, da clases en varias universidades de Bogotá13 y publica ensayos a partir de 1958. En los años 1960, el fin de la dictadura de Gustavo Rojas Pinilla le permite desarrollar aún más sus actividades universitarias y funda el Museo de Arte Moderno de Bogotá en $1962^{14}$.

11 El primer ensayo que publica, El museo vacío, se construye a partir de referencias europeas (empieza por la famosa cita de Valéry sobre la crítica de arte). En este ensayo, desarrolla dos teorías de la historia del arte radicalmente distintas y se pregunta cómo puede utilizarlas para analizar el arte moderno. Se trata de las teorías de Wilhem Worringer y Benedetto Croce. Su visión del arte moderno se acerca más a las teorías de Croce: la creación artística como producto individual y universal, en la cual lo que más importa es la personalidad del artista. El arte no es otra manera de trasmitir nociones o valores que podemos trasmitir de otra manera. Por otro lado, Worringer es famoso por sus esquemas espirituales-históricos: el hombre primitivo, el hombre gótico..., que también le interesan. Esta tentativa por considerar las dos teorías podría estar influenciada por las clases de Francastel, que considera que Croce "n'a retenu qu'une des faces du problème. L'œuvre ne se situe pas simplement par rapport à la pensée d'un individu, mais comme une communication de cette pensée à un entourage" 15 .

Estas dos tendencias guían a Marta Traba durante los primeros años, como afirma en su ensayo. Más generalmente, trata de definir el arte moderno teniendo en cuenta los conceptos teóricos y filosóficos de su época (Bergson por ejemplo).

Aquí volviendo a la escena artística colombiana, la valoración de los artistas nacionales "modernos" por parte de Marta Traba viene asociada a un rechazo violento del folklorismo y del arte político o que lleva un "mensaje" (Traba, 1957: p. 5). Su discurso "occidentalista" ${ }^{16} \mathrm{y}$ su vehemencia, llevaron gran parte de la crítica ulterior a oponerse radicalmente a sus teorías, sin tener en cuenta la clara evolución de su visión crítica a partir de los años 1965 (por ejemplo en: Jaramillo, 2012). Esa nueva orientación teórica de Marta Traba es, paradójicamente, más conocida en los otros países latinoamericanos que en Colombia, donde sobre todo se la recuerda por su primera etapa teórica ${ }^{17}$.

\section{Segunda orientación crítica de Marta Traba: entre los años 1960 y 1980}

14 Entre 1960 y 1966, Marta Traba va desarrollando paulatinamente la idea de que las grandes potencias europeas y norteamericanas amenazan la expresión artística latinoamericana por su presencia en la escena artística del subcontinente $\mathrm{y}$, por consiguiente, Latinoamérica corre el riesgo, retomando las palabras de Adolfo Colombres, de "terminar en un anodino apéndice de Occidente" (Colombres, 1995: 
p. 201). Entonces, Marta Traba descentra progresivamente su discurso teórico para pensar el arte moderno desde Latinoamérica.

Podemos vislumbrar este cambio a partir de 1961, ya que Juan Acha declara sobre su ensayo La pintura nueva en Latinoamérica (1961): "por primera vez se enfocó el arte de nuestros países como totalidad y con un espíritu latinoamericanista [...] con una conciencia ávida de reconocer su identidad cultural mediante la búsqueda de soluciones a los problemas artísticos y sensitivos que nos son comunes" (Acha, 1994: p. 55). Es el inicio de una reflexión que la lleva a considerar las mutaciones artísticas en el subcontinente teniendo en cuenta su contexto socio-cultural, y no solo desde un punto de vista estrictamente estético o artístico ${ }^{18}$.

Tal descentramiento corresponde al contexto de la Revolución cubana - Marta Traba viaja a Cuba en 1966, donde recibe el Premio Casa de las Américas por su primera novela Las ceremonias del verano ${ }^{19}$-, al boom literario latinoamericano, y a su descubrimiento de las obras marxistas (en particular las teorías de Marcuse). También se debe al progresivo desarrollo y maduración en sus escritos de la idea de que el arte latinoamericano pierde su identidad al imitar los modelos europeos y norteamericanos.

17 Tal cambio de punto de vista viene acompañado por la progresiva constitución de un verdadero marco teórico a partir de principios de los años 1970, una construcción en la cual es probable que su encuentro con Ángel Rama en 1966 haya desempeñado un papel decisivo.

18 En su discurso, se puede observar la importancia de la sociología del arte de Francastel : observamos su influencia en el primer periodo de sus escritos, pero también, de otra manera, en este segundo periodo. Lo que la interesa en esta parte de sus ensayos es la sociología del arte, en su sentido más amplio, o sea el hecho de considerar el arte como un reflejo de la sociedad en la que nace.

19 Cuando no encuentra herramientas teóricas en historia del arte para describir ciertos fenómenos plásticos, también recurre a la crítica literaria que adapta a las artes plásticas: encontramos a menudo en sus ensayos citas de Roland Barthes (como cuando retoma su categoría de "hombre estructural" para describir la relación del sujeto creador con su obra en los cuadros de Gerzo, y los conceptos de descomposición y recomposición), Tzvetan Todorov, Maurice Blanchot, etc.

20 Sin embargo, si sigue utilizando algunos análisis de pensadores europeos (sobre todo Francastel y Marcuse), lo hace considerándolos como utillaje adaptable dentro del movimiento de los Estudios Culturales latinoamericanos: sus teorías se acercan entonces a las de Ángel Rama, Antonio Cornejo Polar y Enrique Dussel, grandes pensadores de la identidad latinoamericana de los años 1960-1980. Así es como Marta Traba se inscribe en esta corriente de investigación sobre las Identidades Culturales del subcontinente.

21 Dentro de las diferentes etapas de las teorías sobre las identidades culturales latinoamericanas, según la clasificación de Eduardo Mendieta, podemos ubicar a Marta Traba en el latinoamericanismo post-revolución cubana (tercera etapa en su clasificación), iniciado y teorizado por los intelectuales latinoamericanos (como Darcy Ribeiro, Orlando Fals Borda, Augusto Salazar Bondy o Gustavo Gutiérrez), y no por otros países con intención "imperialista". Este latinoamericanismo de los años 1960-1980 se estructura alrededor de un pensamiento de la emancipación que puede aparecer bajo la 
forma de una "Filosofía de la Liberación" ${ }^{20}$ antiimperialista (desarrollada en particular por Enrique Dussel).

Por otra parte, la crítica de Marta Traba se ubica en un contexto cultural muy preciso, descrito por Antonio Cornejo Polar (Cornejo Polar, 2011: pp. 5-7), entre tres coyunturas centrales: la primera, la serie de cambios socio-políticos de los años 1960, la efervescencia social y cultural; la segunda, la preocupación creciente por la identidad nacional o latinoamericana en el discurso de los intelectuales; y la tercera, la reivindicación de una pluralidad heteróclita que definiría la sociedad y la cultura del subcontinente. En ese contexto, podemos vincular las teorías sobre historia del arte de Marta Traba con las de Rama y de Cornejo Polar sobre la literatura, porque el primero propone una adaptación del concepto de "transculturación" de Fernando Ortiz (Rama, 1987) y el segundo desarrolla el concepto de "heterogeneidad cultural" (Cornejo Polar, 2011).

Si, con su ensayo La pintura nueva en Latinoamérica (1961), Marta Traba empieza a recentrar su interés en el subcontinente latinoamericano - ya que se trata de una de las primeras historias del arte latinoamericano ${ }^{21}$ - es en sus escritos de los años 1970 en los cuales desarrolla su nuevo marco teórico "resistente", Arte latinoamericano actual (1972) y Dos décadas vulnerables en las artes plásticas latinoamericanas (1973) ${ }^{22}$. Sigue defendiendo un arte moderno en América latina, pero en esos escritos hace hincapié en los peligros del "imperialismo" cultural extranjero : así, declara que París y luego Nueva York "han servido a un proyecto imperialista destinado a descalificar las provincias culturales y a unificar productos artísticos en un conjunto engañosamente homogéneo que tiende a fundar una cultura planetaria, nuestra existencia artística ni siquiera se plantea como una probabilidad" (Traba, 1975).

La influencia europea se convierte, en el discurso de Marta Traba, en una forma de "dominación cultural francesa y europea", que asfixia a Latinoamérica que "no ha superado el estado colonial" (Traba, 1972: p.13). Europa era en efecto un modelo dominante hasta los años 1920 (Traba, 1994: pp. 1-11; Bayón, 1980: pp. 5-33), época en la cual los pintores europeos venían a América para difundir su estilo académico (por ejemplo el pintor francés Raymond Monvoisin o el alemán Ernesto Kirchbach), o dirigir las Academias de Bellas Artes. Marta Traba les reprocha a los artistas latinoamericanos de los años 1960 el hecho de que sigan sometiéndose a ese antiguo modelo y a esos cánones artísticos al irse a formarse a Europa ${ }^{23}$.

Pero su denuncia más virulenta la hace en contra de la "colonización" o "satelización" artística llevada a cabo por Estados Unidos, que sucede a la de Europa en el subcontinente. En efecto, en su ensayo más famoso, Dos décadas vulnerables..., Marta Traba denuncia la llegada del pop art a América latina en los años 1960-1970, que no es un estilo o una estética (Traba, 2005: p. 143), sino "la imposición de sistemas de civilización [...] típica de los imperialismos" (Traba, 2005: p. 63), ya que, según ella, se trata de un sistema cultural global, que representa una sociedad de consumo, industrial y tecnológica, y que no corresponde, en aquella época, a la situación socioeconómica de América latina. En su análisis, explica que el pop art vehicula, por los medios masivos de comunicación, la ideología tecnocrática y consumista de esta "sociedad opresora" 24 . Recurre a una metáfora o un esquema lingüístico para subrayar, desde esta perspectiva, la diferencia entre la influencia del arte europeo, un "signo" susceptible de ser resemantizado por los que lo utilizan - podemos hablar de una readaptación local de esquemas exteriores -, y la "dominación imperialista" (Traba, 2005: p. 61) del arte 
norteamericano, que emite "señales" de comunicación "un mero indicador mecánico, pauperizado, capacitado para marcar un camino a seguir pero impotente para abrir el complejo meollo de una estructura de sentido como es el lenguaje" (Traba, 2005: p. 64$)^{25}$.

Al contrario, las obras de los artistas latinoamericanos deben, según ella, inspirarse en la sociedad y el espacio en los cuales son creadas. No se trata solamente de representar un tema latinoamericano (objetos, personas o lugares), sino que también hay que elegir un "medium" en armonía con la sociedad que lo ve nacer - el "medium", concepto desarrollado por Hans Belting, designa los medios históricamente determinados para crear imágenes ${ }^{26}$. Según Traba, entonces, la emancipación los artistas latinoamericanos está vinculada con la elaboración de un "medium" que les sea propio, elaborando o adaptando estilos y formas nuevos o del exterior. Como decía José Carlos Mariátegui en 1928, hablando de literatura: "Al poeta no le basta traer un mensaje nuevo. Necesita traer una técnica y un lenguaje nuevo también" (Mariátegui, 2005: p. 276). Tal elaboración de artes nuevas, a la vez modernas y latinoamericanas, permitiría a América latina protegerse del imperialismo artístico. Éstos son los fundamentos de la "teoría de la resistencia" de Marta Traba, que construye a partir de las propuestas estéticas existentes que adaptan y subvierten los modelos dominantes, y vuelven a tener, de este modo, la capacidad de comunicar con la sociedad que los ve nacer (Crousier, 2015: pp. 209-220).

En su ensayo Dos décadas vulnerables... Marta Traba trata de compilar las diferentes formas de resistencia artística en el subcontinente bajo la forma de un panorama general, siendo consciente de la diversidad de las propuestas estéticas de los artistas ${ }^{27}$. Entre los artistas "resistentes" cuya obra analiza, analizaremos la obra de tres pintores colombianos. El primero es Alejandro Obregón, y en particular su serie de cuadros titulados Torocóndor. En estas obras el artista por un lado inventa y desarrolla su propio estilo pictórico: con colores que se organizan alrededor de grandes núcleos y luego se diluyen; y por otro lado representa una fiesta tradicional andina, que consiste en reproducir metafóricamente el combate entre España y América atando un cóndor a un toro para que se enfrenten en un combate sangriento. Otros artistas, como Fernando Botero, subvierten en su obra las influencias norteamericanas o europeas, o adoptan un estilo radicalmente opuesto. El pintor colombiano se inscribe en contra de la estética plana del póster, dando un volumen y unas dimensiones desmesurados a lo que representa, e incluso cuando reproduce obras maestras europeas, se aparta de los originales y les imprime su propia visión, deformándolos (como en Monalisa, 1977). Asimismo, Beatriz Sarlo, reproduce obras de Vermeer con colores vivos sobre objetos o muebles de la vida cotidiana, quitándoles su atmósfera solemne y dándoles una nueva función, la de los objetos en los que pinta. En 1964, propone varias adaptaciones del cuadro La encajera (1669-1671): Encajera almanaque Pielroja, Encajera en la noche de la rendición de Breda, Un busto para la encajera del imperio, Encajera mona, Encajera en la playa; y en 1973, realiza un montaje bajo la forma de una pintura de esmalte en una cesta de mimbre, Encajera in situ. Ésos solo son unos pocos ejemplos entre la multitud de pintores cuya obra analiza Marta Traba.

Entre las estrategias de resistencia, terminaremos evocando otro tipo de ejemplo, sacado de una novela de Marta Traba, que muestra una equivalencia literaria a sus teorías de crítica de arte - cabe señalar, más generalmente, que observamos muchas influencias de sus consideraciones sobre las artes plásticas en su literatura, y su 
evolución temática es paralela ${ }^{28}$. El siguiente fragmento de la novela La jugada del sexto día (1970) ilustra, en literatura, una posible estrategia de resistencia pictórica de los artistas latinoamericanos: una apropiación literaria de los cuadros de Vermeer, una forma de transculturación.

- Muchos de mis cuentos giran sobre el mismo tema [...] un tema que me obsesiona ; la transformación que sufre un cuadro a medida que lo mira el coleccionista. [...] el dueño del paisaje, o de la escena flamenca, o lo que sea, comienza a ver operarse en ellos los cambios más extraños ; siempre son terribles. [...]

- ¿ Por qué esa saña especialmente contra los cuadros ? - dijo Aldo.

- Hemos aprendido que hay patrimonios - contestó Pablo encendiendo un cigarrillo-. Quiero decir, en otras partes hay patrimonios. Nosotros no los tenemos; no tenemos nada. Tal vez sea una venganza. Quizás el deseo de mostrar que no hay nada estable, nada perdurable. Por eso descompongo lo que lógicamente no es susceptible de descomposición : las cosas.

[...] Lo que pasa en los cuadros de mis cuentos es irrefrenable; un cuadro de Vermeer, por ejemplo, se va llenando de gente, hasta que destruyen a la solitaria protagonista. Puede ser que la devoren. (Traba, 1970.1: pp. 129-130)

Este fragmento revela que uno de los objetivos de Marta Traba, en su práctica recurrente de la ékfrasis, podría ser el mismo que el de Pablo: apropiarse de un patrimonio, no para destruirlo, sino para hacerlo suyo, por medio de una serie de transculturaciones. Además, el joven evoca el acto de antropofagia en su descripción, que evidentemente remite al movimiento antropófago brasileño, que consiste en "tragar" el legado europeo para apropiarse de él; asimismo, menciona la posibilidad de una apropiación de las obras por su "digestión".

30 Esta alusión metaliteraria a la técnica de la composición literaria de Marta Traba está directamente vinculada con sus escritos de crítica de arte, como acabamos de ver en la obra de Beatriz González. También puede hacernos pensar en los cuadros del pintor peruano Herman Braun-Vega, que desvía y subvierte permanentemente obras maestras europeas o norteamericanas, al mezclar diferentes cuadros entre sí, o, como en esta cita, al añadir unos personajes y al cambiar el contexto de algunas obras: es el caso, por ejemplo de Buenos días Vermeer, también titulado Norte-Sur, de 1981, en la que se apropia del cuadro Mujer con una jarra de agua (alrededor de 1662), para ambientarlo en un contexto latinoamericano.

31 Para terminar con la segunda orientación de Marta Traba, en aquella época, después de haber viajado por toda América latina, también hace el inventario de las diferentes tendencias artísticas del subcontinente en los años 1960-1970 (Traba, 2005: pp. 158-204), bajo la forma de una cartografía: describe, por una parte, los países o las capitales que desean asimilar los modelos de arte moderno difundidos por los polos occidentales, que califica de "áreas abiertas" (Traba, 2005: pp. 158). Se trata de zonas que conocen un importante desarrollo económico y, por consiguiente, numerosos intercambios con el extranjero, tales como Argentina (pero sobre todo Buenos Aires), Caracas o São Paolo. Por otra parte, califica de "áreas cerradas" (Traba, 2005: pp. 185) los lugares o países donde la tradición sigue teniendo un peso importante, y cuyos intercambios con el extranjero son más limitados (como el Perú, Colombia, etc.). En estas zonas, la conciencia de la identidad cultural está vinculada con estas características. Según Marta Traba, es en estas áreas cerradas donde los artistas elaboran las estrategias de resistencia más variadas.

En cada área, la crítica pone de realce y explica las obras vinculándolas con la identidad regional. Analiza por ejemplo la obra de Szyszlo en el Perú, Cuevas y Toledo en México, 
Jacobo Borges y Carlos Prada en Venezuela, Abularach en Venezuela, Hermenegildo Sábat y Roberto Aizemberg en Buenos Aires...

Sin embargo, pese a este cambio radical de posición crítica en cuanto a las artes latinoamericanas, nunca abandona a los artistas europeos, ya que sigue publicando artículos y ensayos sobre los que le causaron impresión, en particular En el umbral del arte moderno, en 1973.

\section{Conclusión}

Le evolución del pensamiento crítico de Marta Traba es compleja. Por una parte, se trata de una reconsideración del contexto de producción de las artes latinoamericanas: ya no solamente busca despertar y estimular un arte latinoamericano moderno, sino inscribir la cuestión estética en la actualidad social y cultural, para pensarla como separada o distinta de las culturas extranjeras. Pero por otra parte, esta reconsideración viene acompañada de un cambio de escala, desde el arte colombiano hasta problemáticas más generales que se plantean en el subcontinente en su conjunto, y que supone por parte de Marta Traba, frente a tal heterogeneidad de las artes latinoamericanas, un considerable esfuerzo de síntesis conceptual.

Esta doble evolución, de la cual Marta Traba es consciente (como lo muestra su desacuerdo con Jorge Romero Brest a partir de $1970^{29}$ y el hecho de que haya criticado, en su artículo "Arrar en tierra" de 1974 (Traba, 1974: pp. 6-10), sus propias primeras teorías eurocéntricas e internacionalistas), no es una renuncia: no se trata de rechazar los modelos artísticos europeos y su tradición estética, sino de desprenderse de un mecanismo de imitación. En este sentido, las alusiones a Europa en la obra trabiana son ambivalentes, entre el apego que expresa continuamente por obras, artistas, teorías y lugares de referencia, y el deseo de autonomía que se encuentra en el centro de sus teorías culturales. Por eso podemos ver en el conjunto de la obra trabiana y en su evolución una síntesis de los principales debates sobre la definición del arte moderno en América latina y, en su cartografía, un primer intento por explicar los puntos de contacto y divergencia entre las diferentes escenas del arte latinoamericano de su época.

\section{BIBLIOGRAPHIE}

Acha, Juan (1994), Huellas críticas, Universidad del Valle / Instituto cubano del libro, Cali / La Habana.

Araújo de Vallejo, Emma (éd.) (1984), Marta Traba, Ediciones del Museo de Arte Moderno Planeta, Bogotá.

Bayón, Damián (1980), América latina en sus artes, Siglo XXI Editores, México [1974].

Bazzano-Nelson, Florencia (2000), Theory in Context: Marta Traba's art Critical Writings and Colombia, 1945-1959, University of Texas, Austin, University of New Mexico, Albuquerque. 
Bazzano-Nelson, Florencia (2005), "Marta Traba: Internationalism or regional resistance", Art Journal, vol. 64, 4, pp. 87-89.

Bazzano-Nelson, Florencia (2010), Marta Traba en circulación, Editorial Universidad Nacional de Colombia, Bogotá.

Belting, Hans (2004), Pour une anthropologie des images, Éditions Gallimard, Paris.

Colombres, Adolfo (1995), "El arte en la emergencia civilizatoria de América latina”, en: Picotti, Diana (ed.), Pensar desde América, Catálogos Editora, Buenos Aires, pp. 201-209.

Cornejo Polar, Antonio (2011), Escribir en el aire. Ensayo sobre la heterogeneidad socio-cultural en las literaturas andinas, CELACP - Latinoamericana Editores, Lima [1994].

Crousier, Elsa (2015), “Crises de l'art moderne latino-américain, 1920-1980: le rôle de Marta Traba dans la rupture et la recherche d'un nouvel ordre artistique", en: Egger, Carole, Palomar, Gregoria, Reck, Isabelle (éds.), Crises dans le monde ibérique et ibéro-américain, ReCHERche $n^{\circ} 15$, Presses Universitaires de Strasbourg, Strasbourg, pp. 209-220.

Dussel, Enrique (2004), “Transmodernidad e interculturalidad (interpretación desde la filosofía de la liberación)”, La Jornada, 347.

Dussel, Enrique (2010), “De la philosophie de la libération”, entrevistado por Fátima Hurtado y traducido por Marine Gallois-Lacroix, Cahiers des Amériques latines, 62, pp. 37-46. URL : https:// cal.revues.org/1525\#ftn1.

Eco, Umberto (1968), Apocalípticos e integrados ante la cultura de masas, trad. Andrés Boglar, Barcelona, Lumen.

Giraldo, Efrén (2007), Marta Traba: Crítica del arte latinoamericano, La Carreta Editores, Medellín.

Giraldo E., Sol Astrid (1998), “La Papisa del arte. Hace quince años murió la polémica crítica”, El Espectador, Bogotá, 29/11/98.

Giunta, Andrea (1995), “Strategies of Modernity in Latin America”, en: Mosquera, Gerardo (éd.), Beyond the Fantastic. Contemporary Art Criticism from Latin América, Institute of International Visual Arts, London, pp. 53-67.

Gómez Echeverri, Nicolás (2008), En blanco y negro. Marta Traba en la televisión colombiana, 1954-1958, Ediciones Uniandes, Bogotá.

Jaramillo, Carmen María (2012), Fisuras del arte moderno en Colombia, Alcaldía Mayor de Bogotá Fundación Gilberto Alzate Avendaño, Bogotá.

Mariátegui, José Carlos (2005), Siete ensayos de interpretación de la realidad peruana, Orbis Ventures S.A.C., Lima [1928].

Mosquera, Gerardo (ed.) (1995), Beyond the Fantastic. Contemporary Art Criticism from Latin América, Institute of International Visual Arts, London.

Picotti, Diana (ed.) (1995), Pensar desde América, Catálogos Editora, Buenos Aires.

Pizarro, Ana (éd.) (2002), Las grietas del proceso civilizatorio: Marta Traba en los sesenta, LOM Ediciones, Santiago.

Rama, Ángel (1987), Transculturación narrativa en América Latina, Siglo XXI Editores, México [1982].

Rodríguez Morales, Ricardo (2000), "Plástica y Prisma: dos revistas de arte de los años cincuenta", Boletín cultural y bibliográfico, vol. 37, 55 . 
Romero Brest, Jorge (1984), “Sobre el punto de partida de Marta Traba”, en: Araújo de Vallejo, Emma (éd.) (1984), Marta Traba, Ediciones del Museo de Arte Moderno - Planeta, Bogotá.

Serrato Ramírez, Melissa (2013), “50 años del MamBo, un museo que nació al pulso”, El Tiempo, 27/02/2013. URL: www.eltiempo.com/archivo/documento/CMS-12621041. Fecha de consulta: $24 / 05 / 2019$.

Traba, Marta (1945), "En el aniversario del Museo Nacional de Bellas Artes”, Anuario Plástica, Buenos Aires, pp. 52-53.

Traba, Marta (1946), “El Salón de la Asociación Estímulo”, Anuario Plástica, Buenos Aires.

Traba, Marta (1957), “Arte y mitología”, Intermedio, p. 5.

Traba, Marta (1961), La pintura nueva en latinoamérica, Ediciones Librería Central, Bogotá.

Traba, Marta, Díaz, Hernán (1963), Seis artistas contemporáneos colombianos, Edición de Antares, Bogotá.

Traba, Marta (1966), El son se quedó en Cuba, Ediciones Reflexión, Bogotá.

Traba, Marta (1970.1), La jugada del sexto día, Editorial Universitaria, Santiago de Chile.

Traba, Marta (1970.2), “Réquiem (¿anticipado?) para Romero Brest”, Marcha, Montevideo, 03/07/1970.

Traba, Marta (1972), Arte latinoamericano actual, Ediciones de la biblioteca de la Universidad Central de Venezuela, Caracas.

Traba, Marta (2005), Dos décadas vulnerables en las artes plásticas latinoamericanas, 1950-1970, Siglo XXI Editores, Buenos Aires [1973].

Traba, Marta (1974), “Arar en tierra”, Artes Visuales, México, pp. 6-10.

Traba, Marta (1975), “Somos latinoamericanos”, ponencia presentada en la Universidad de Texas, Austin, en 1975, publicada por Damián Bayón en: El artista Latinoamericano y su Identidad, Monte Ávila Editores, Caracas, 1977.

Traba, Marta (1994), Arte de América latina 1900-1980, Ediciones Banco Internacional de Desarrollo, Washington.

Verlichak, Victoria (2001), Marta Traba, una terquedad furibunda, Editorial Universidad Nacional Tres de Febrero - Fundación Proa, Buenos Aires.

Zea, Gloria (éd.) (1994), El museo de arte moderno de Bogotá, Museo de Arte Moderno de Bogotá - El Sello Editorial, Bogotá.

\section{NOTES}

1. Sobre este tema y la bibliografía correspondiente, véase la síntesis de Florencia BazzanoNelson (BAZZANO-NELSON, 2005).

2. Retomamos aquí las conclusiones del doctorado de Florencia Bazzano-Nelson. Su análisis se centra en la crítica de Marta Traba redactada entre 1945 y 1959, en las revistas y los periódicos colombianos El Tiempo, Mito, Plástica y Prisma (BAZZANO-NELSON, 2000).

3. Cursa una carrera de letras porque en aquella época no existía una facultad de Historia del arte, y se gradúa en 1944.

4. Estos artículos son: "En el aniversario del Museo Nacional de Bellas Artes" y "El Salón de la Asociación Estímulo” (TRABA, 1945 y TRABA, 1945). 
5. "Un salón como el que nos toca comentar significa retardo" (TRABA, 1946: pp. 30-31).

6. Marta Traba trabaja con Jorge Romero Brest durante casi un año. Deja su puesto cuando se va a Europa, en octubre de 1948, pero sigue siendo miembro de la asociación "Ver y Estimar" hasta noviembre de 1953, fecha de la última publicación de la revista Ver y Estimar (VERLICHAK, 2001: pp. 76-77).

7. Jorge Romero Brest afirma, sobre Marta Traba: "Ella decía, muy generosamente, que había sido mi discípula, pero en verdad, más que una discípula fue una colaboradora eficientísima cuando a consecuencia del primer curso fundé la revista Ver y Estimar, de la que fue secretaria de redacción" (ROMERO BREST, 1984: p. 8).

8. Añade: "La filosofía que estudiábamos partía de los griegos a quienes veíamos como nuestros orígenes más remotos", para mostrar el eurocentrismo en su formación académica y la exclusión de una filosofía latinoamericana. (DUSSEL, 2004: p. 1).

9. Otros debates famosos caracterizan la crítica de Marta Traba, como el que la opone a Gonzalo Ariza en 1958, y es, de alguna manera, una anticipación de la famosa oposición entre Julio Cortázar y José María Arguedas. (BAZZANO-NELSON, 2000 : pp. 473-515).

10. Cita la famosa frase de André Malraux (Les conquérants): "No hay genio copista, no hay genio servil”, en el artículo "El genio anti-servil” (ARAújo DE VALLEjo, 1984: pp. 149-150).

11. Marta Traba presenta varios programas televisivos de historia del arte, sobre todo entre 1954 y 1958, como lo muestra Nicolás Gómez Echeverri. En 1954: "La rosa de los vientos"; en 1954 y 1955: "El museo imaginario"; en 1955: "Una visita a los museos" y "El ABC del arte"; en 1957: "Cursos de Historia del arte" y "Ciclo de conferencias"; en 1959: "Viaje alrededor del arte"; et en 1966: "Puntos de vista" (programa suspendido en septiembre de 1966 por razones políticas). Otras difusiones tienen lugar ulteriormente. En 1983, Marta Traba vuelve a grabar un programa de Historia del arte para la televisión colombiana, "Historia del arte moderno contada desde Bogotá", difundido en 1984, de modo póstumo (GóMEZ ECHEVERRI, 2008: pp. 19-29). Sobre esta temática, véase también el ensayo de Florencia Bazzano-Nelson (BAZZANO-NELSON, 2010: pp. 12-56). 12. En los años 1950, principalmente en El Tiempo, Plástica et Mito, como lo muestra Florencia Bazzano-Nelson en su doctorado. Marta Traba también crea su propia revista de arte (durante el año 1957) - Prisma - que se inspira a la vez en Ver y Estimar y en Plástica. Ricardo Rodríguez Morales afirma, sobre las revistas Plástica y Prisma: "desempeñaron en su momento un papel importante en la afirmación de un movimiento artístico y estético de verdad contundentes" (RODRÍGUEZ MORALES, 2000).

13. En Bogotá, en la Universidad de América, la Universidad de Los Andes y la Universidad Nacional.

14. Sobre el contexto de Colombia en los años 1960, véase: "Marta Traba, la transgresión" (PIZARRO, 2002: pp. 7-16); y sobre el Museo de Arte Moderno de Bogotá (ZEA, 1994).

15. Observaciones publicadas posteriormente en 1965, en La réalité figurative.

16. En el sentido en el cual lo emplea Walter Mignolo, el "occidentalismo" es una forma de colonialidad del saber.

17. Porque en aquella época vivía en Bogotá donde tenía una influencia directa sobre la vida artística del país.

18. Véase el ensayo de Efrén Giraldo que, si bien no separa tanto las dos etapas del pensamiento crítico de Marta Taba, ofrece un buen análisis de esta segunda etapa (GIRALDo, 2007: p. 98).

19. Publica varios artículos y presenta una conferencia sobre Cuba ese mismo año, en los que aprueba los resultados de la Revolución cubana, y admira las artes y la arquitectura del país (TRABA, 1966).

20. La "Filosofía de la Liberación" aparece en los años 1970, y su objetivo es definir una identidad latinoamericana que se base en la realidad local del subcontinente. Si bien se trata de una definición filosófica que busca descentrar los discursos producidos sobre América latina, también 
es política, porque, para Enrique Dussel, la Filosofía de la Liberación está pensada desde el oprimido latinoamericano (DUSSEL, 2010: pp. 37-46).

21. Se suele considerar que este ensayo de Marta Traba es la primera historia del arte latinoamericano, como lo afirma Gerardo Mosquera: "Marta Traba published the first book to approach Latin American art in a global manner, attempting to give the subject some conceptual unity" (MOSQUERA, 1995: p. 10). Sin embargo, antes, Ángel Guido había publicado en 1944 Redescubrimiento de América en el arte, y en 1945 Felipe Cossio del Pomar había redactado unos capítulos sobre arte latinoamericano en La rebelión de los pintores: ensayo para una sociología del arte. 22. También observamos esta nueva orientación teórica en los ensayos dedicados a la obra de unos artistas precisos (a menudo colombianos), como Los muebles de Beatriz González (1977), Los grabados de Roda (1977), Elogio de la locura (1986)...

23. En La pintura nueva en Latinoamérica, habla de una "sumisión vergonzosa" de esos artistas, porque "Los colonialismos [...] parten de los colonos y no de los colonialistas" (TRABA, 1961: p. 43).

24. Retoma las teorías de Marcuse (El hombre unidimensional y Eros and Civilization: A Philosophical Inquiry into Freud).

25. Marta Traba utiliza aquí la definición de Umberto Eco (ECO, 1968: véase en particular el capítulo 5, "Estructura del mal gusto").

26. Se trata de los "mediums" por los cuales las imágenes toman forma y aparecen (cuadros, películas, herramientas...); incluimos el estilo de los artistas en este concepto, ya que es una de las maneras de darles forma a las imágenes (BELTING, 2004: p. 7).

27. Hubo pocos movimientos colectivos de artistas latinoamericanos; entre ellos, cabe señalar el muralismo mexicano, el movimiento antropófago brasileño o la Escuela del Sur de Torres García en Uruguay (GIUNTA, 1995: pp. 53-67).

28. No podemos explicar aquí la totalidad de la evolución temática y geográfica de sus novelas, desde Europa hasta América latina, pero es interesante señalar que, en ellas, la autora pone en escena a unos personajes que paulatinamente dejan de ser fascinados por la ciudad de París (Los laberintos insolados, 1967), hasta transformar el "París era una fiesta" (que cita en Las ceremonias del verano, 1966), en "Santiago era una fiesta" (en Conversación al sur, 1981), haciendo del Chile de Salvador Allende un nuevo centro, ya que fue allí donde se intentó forjar una alternativa política, social y también cultural.

29. Porque "las experimentaciones del Di Tella excluían cualquier relación entre la obra, el país y el continente” (TRABA, 1970.2).

\section{RÉSUMÉS}

El objetivo de este artículo es analizar la evolución de la crítica de arte de Marta Traba (crítica de arte argentino-colombiana, 1923-1983), porque las diferentes teorías que defendió entre los años 1945 y 1980 son representativas de los puntos de contacto y divergencia entre las escenas del arte latino-americano de su época.

Se trata de un estudio centrado en un caso específico, que reúne las dos principales tendencias teóricas del momento y refleja la evolución del pensamiento crítico latinoamericano entre 1945 y 1980.

Marta Traba es un personaje central de la teoría y la historia del arte latinoamericano, y podemos destacar en su obra dos períodos críticos. Primero, entre 1945 y los años 1960, Marta Traba 
adopta un punto de vista eurocéntrico, que toma como referencia el arte moderno europeo; pero a partir de los años 1960-65, dándose cuenta del peligro que representa la internacionalización de las artes latinoamericanas, empieza a defender un arte moderno latinoamericano, que refleje o respete las identidades culturales regionales.

Mostraremos en este artículo en qué medida se puede vincular esta evolución teórica con la definición del arte moderno en América latina a lo largo del siglo XX..

This article discusses the importance of the production and thinking

INDEX

Mots-clés : Marta Traba, crítica de arte, Argentina, Colombia, historia del arte latinoamericano. 